\title{
VOZES DA CIÊNCIA. DISCURSO CIENTÍFICO E ENUNCIAÇÃO
}

\author{
Maria Aldina MARQUES ${ }^{1}$
}

\section{INTRODUÇÃO}

O discurso científico tem sido objeto de estudo privilegiado, entre os investigadores que trabalham na área dos discursos. É um discurso constituinte, como propuseram Maingueneau \& Cossutta ${ }^{2}$, num conceito elaborado a fim de delimitar e individualizar um conjunto de tipos discursivos com uma função fundadora, a partir de uma "intuition banale", a de que "il y a dans toute société des types de paroles qui font autorité, qui sont reconnues comme donnant sens aux actes de l'ensemble de la collectivité" . A análise do discurso, na sua aceção mais ampla, não poderia, pois, ignorar a centralidade desta área de atividade social-discursiva. A importância dos discursos científicos advém de que não são meros veículos, transparentes e exteriores à construção do saber científico, escrever ciência não é só falar sobre ciência, é fazer ciência, porque o conhecimento científico se constrói em discursos.

Outras áreas de investigação sobre a linguagem e o discurso, de que os estudos da língua para fins específicos (LSP) no quadro da linguística aplicada são exemplo, têm no discurso científico, ou no discurso académico, também, um objeto central de investigação ${ }^{4}$.

Pretende-se, neste trabalho, a propósito do Discurso Científico, discutir as características do género artigo científico, considerado um dos seus géneros nobres. Esta preponderância está, aliás, em franco crescimento, no quadro dos novos sistemas de avaliação da produção científica, ancorados na indexação em bases de dados como a Scopus, ou a Web of science.

E-mail: mamarques@ilch.uminho.pt

2 Maingueneau \& Cossutta (1995).

3 Maingueneau (2014, p.151).

4 Swales 1990; Hyland 1996a, 1996b, 2001 e 2002, entre outros. Swales (1990, p.1) apresenta como objetivo central do seu texto "to offer an approach to the teaching of academic and research English.” 


\section{ENUNCIAÇÃO, SUBJETIVIDADE E DISCURSO CIENTÍFICO}

A presente análise enquadra-se numa abordagem pragmático-enunciativa dos discursos. É a contextualidade intrínseca do sentido discursivo que sustenta a pluralização do sintagma "dos discursos", como se encontra em autores como Charaudeau (2002), Hailon (2012), Adam (2010 e 2012), Marques (2015), entre outros. ${ }^{5}$ A opção pela pluralização de discursos tem implicações, nomeadamente, na importância teórica e metodológica de assumir a heterogeneidade dos discursos, objetos de análise empíricos (Marques, 2015: 110). ${ }^{6}$ É um posicionamento teórico que privilegia a linguagem em uso e os discursos como práticas sociais de comunicação. Daí a centralidade teórica e metodológica dos conceitos de tipo e género de discurso.

Entre outras constrições comuns aliás a qualquer enunciação, mas com um grau de comprometimento forte no que ao discurso científico concerne, Maingueneau (2000:11) sublinha, entre outras questões, que «...no âmago dos discursos constituintes, os falantes não podem ignorar questões básicas como quem está autorizado a falar ou a ser destinatário...». Seguindo tal indicação, vamos debruçar-nos sobre uma vertente fundamental das vozes do artigo científico, o processo de referenciamento ${ }^{7}$, para pôr em relevo a "fala de autoridade» que aí se constrói, especificamente, onde e como se constrói, tendo em conta as práticas discursivas de natureza científica num contexto determinado. Destaca-se neste processo de referenciamento, isto é, de referência bibliográfica e citação a própria voz do locutor que constrói o seu lugar, a sua imagem, ao posicionar-se relativamente a essas vozes convocadas. O referenciamento é obrigatório, tem mesmo o estatuto de parâmetro de género, como reconhecem Fløttum (2006: 37) e Grossmann (2010:8). ${ }^{8}$

5 Esta questão tem a ver com o vasto campo da análise do discurso e das diversas disciplinas, áreas, abordagens que aí confluem. É uma questão que sobretudo dá conta da transdisciplinaridade do objeto discurso. Remete-se a Maingueneau (2006), mais uma vez, quanto à questão da Análise do Discurso e das correntes e disciplinas que aí confluem.

6 Refira-se, ainda, o texto seminal de Authier-Revuz (1982 e 1984) e, mais recentes, Fonseca (1994) ou Adam (2010), sobre o estatuto teórico do conceito de heterogeneidade.

7 Usamos o termo referenciamento, menos comum que referenciação, para evitar ambiguidade com o conceito de referenciação como processo de construção dos objetos do discurso.

8 Fløttum (2006:37) usa apenas o termo "referências bibliográficas": "there is in fact 
Desde Benveniste, pelo menos, que a presença do locutor no discurso, na enunciação segundo o autor, ${ }^{9}$ tem sido objeto constante de investigação. $\mathrm{O}$ trabalho desenvolvido por Rabatel (2015) sobre enunciação e dialogismo reformula, em questões fundamentais, as teorias de Ducrot (1984) e Bakhtine (1984). De Ducrot, retoma os conceitos de locutor e enunciador, para os repensar: o locutor-enunciador (L/E), a que o autor pode ou não identificar-se, é responsável pela coerência dialógica do discurso ${ }^{10}$, em função dos pontos de vista [PDV] que convoca, quer se trate de outros locutores-enunciadores (1/e) (discurso relatado) quer de enunciadores segundos, não locutores (e). É uma conceção hierarquizada dos PDV que abre espaço para a definição da postura do enunciador, em termos de sobre-enunciação, subenunciação e coenunciação ${ }^{11}$ (Rabatel, 2004, 2012, 2015, entre outras publicações) e para o valor argumentativo das vozes que o locutor traz para o discurso. A atenção à enunciação põe em causa o pressuposto clássico, estruturalista, da transparência da linguagem ou, a partir de outras perspetivas de abordagem, da sua objetividade. Com efeito, a construção dos sentidos dos discursos é um processo que envolve os interlocutores e a subjetividade, constitutiva da interação, é negociada e construída como intersubjetividade entre o eu e o(s) outro(s). Estamos longe de uma conceção da língua como descrição objetiva da realidade, e especificamente, estamos longe da "objetividade absoluta" reclamada tradicionalmente para o discurso científico, ${ }^{12}$ abordado agora como práti-

one obvious typical trait: bibliographical references. There are always bibliographical references in one form or another in every research article." Segundo Grossmann (2010:8), «Scientific texts can be described as multiple-referenced discourse».

9 «La présence du locuteur à son énonciation fait que chaque instance de discours constitue un centre de référence interne. Cette situation va se manifester par un jeu de formes spécifiques dont la fonction est de mettre le locuteur en relation constante et nécessaire avec son énonciation.» (Benveniste, 1970: 14).

10 Fløttum (2002: 342) fala de coerência polifónica.

${ }^{11}$ Rabatel (2004) analisa estas relações a propósito do discurso relatado. Cabe ainda referir que a postura de sobre-enunciação é considerada, por Grossmann \& Rinck (2004). como característica do género artigo científico: "La notion de surénonciation ouvre des pistes intéressantes pour analyser la manière dont la dimension énonciative des textes joue un rôle argumentatif, dans le sens où la hiérarchisation énonciative favorise l'adhésion au point de vue de l'auteur. Le discours rapporté et le dialogisme, aux fondements de la posture de surplomb de Ll/El, peuvent en effet être envisagés comme participant d'une visée argumentative légitimant le discours, c'est-à-dire montrant sa qualité et sa pertinence scientifiques. "

12 Retomo Rabatel (2018 :17) para recusar a ideia de um relativismo absoluto, a partir 
ca científica, mas também como prática social, um posicionamento teórico que tem, certamente, implicações na análise dos discursos científicos. Porque a construção do conhecimento científico é uma prática social, afirma-se a subjetividade constitutiva dos discursos científicos (Grossmann \& Rinck, 2004, Rinck, 2010, Swales 2004, Fløttum, 2006, entre outros). ${ }^{13}$

Contudo, deve salientar-se, a subjetividade está presente, mas não é qualquer forma de subjetividade. ${ }^{14}$ É a subjetividade prevista e possível, sancionada pelas comunidades científicas enquanto modos de dizer ratificados pela comunidade, integrando-se, por isso, nos parâmetros de género, especificamente no estilo de género. ${ }^{15}$

O discurso científico não é um discurso simplesmente “objetivo" é, antes, um discurso objetivado (por alguém, credibilizado para o fazer). O efeito de objetividade discursiva resulta de um conjunto de escolhas do locutor. O processo de objetivação é, por um lado, um processo linguístico - e o apagamento enunciativo funciona desse modo -, mas é também uma objetividade conseguida pelo modo como o quadro teórico, a metodologia, os objetivos, a análise são discursivamente representados. O discurso científico é marcado pelo rigor, pelo quadro teórico e metodológico necessários à validade da análise realizada. Charaudeau (2016: 551) sublinha, a propósito, a finalidade demonstrativa do discurso científico. Ora, o estilo do género artigo científico é determinado por estas características. ${ }^{16}$

Como este posicionamento teórico tem implicações na própria análise dos discursos científicos, torna-se pertinente refletir sobre que vozes são ouvidas e de

destes pressupostos. Como refere o autor, "Ma conception du PDV récuse la coupure radicale et quasi métaphysique entre un PDV nécessairement limité $v s$ la vérité, universelle et indépendante de tout point de vue (Plantin 2016 : 70-71). L'approche perspectiviste, historicisée, du PDV rend compte de la relativité des savoirs, sans verser dans le relativisme absolu»

13 Para Flotum (2006: 19), não existe "academic discourse [scientific discourse] as objective neutral and deprived of personal traces. Na terminologia de Rabatel (2005), um discurso é tendencialmente objetivante ou subjetivante.

14 Prestigiacomo (2016: 262) chama atenção para possibilidade de manipulação, quando o locutor "se inclina para un modelo expressivo diferente".

15 Sobre parâmetros de género ver Adam (2015) e Maingueneau (2014).

16 No caso vertente, e como refere Gusfield (1976:17) "The style of non-style is itself the style of science". 
que modo estão presentes na materialidade dos discursos. ${ }^{17}$ É, aliás, este enquadramento que explica o interesse de que as categorias deíticas têm sido alvo. Mas locutor não está apenas presente nas marcas deíticas de primeira pessoa, está nas vozes que escolhe trazer para o discurso, bem como nos modos de enunciação selecionados; está ainda nas escolhas lexicais ao serviço da construção do universo discursivo, pois, como lembra Rabatel (2015:34), a enunciação é coextensiva à referenciação.

No caso vertente, será analisado, como já referido, o referenciamento no artigo científico, um modo específico de convocar outras vozes, e uma categoria de marcas discursivas que atualizam um parâmetro do género.

Para isso foi constituído um pequeno corpus de 8 artigos científicos (ver anexo), de acordo com os seguintes critérios:

(1) Artigos científicos publicados online em revistas portuguesas ${ }^{18}$ com revisão por pares.

(2) Autoria de investigadores seniores, (re)conhecidos na sua comunidade de investigação, as Ciências da Linguagem.

São critérios que nos permitem classificar os artigos selecionados como exemplares da respectiva comunidade científica. O critério (2), decorrente do estatuto social do locutor, é de natureza socio-discursiva, mas condiciona a construção linguístico-discursiva, isto é, as escolhas realizadas desde o nível macro ao nível micro, dadas, nomeadamente, as constrições do género discursivo. Está em causa uma competência comunicativa alta, no que concerne ao género em análise. Deliberadamente, não foi considerado como critério de constituição do corpus a pertença a bases de dados como a Scopus e similares. Quanto ao critério (1), não

17 Segundo a tradição, a presença do locutor é não-científica. Ver a síntese feita por Reutner (2010), a propósito da presença do locutor nas categorias deíticas usadas.

18 Não são muitas as revistas científicas escritas em português. Nomeadamente na área das ciências ditas "duras", a maior parte dos artigos são escritos em inglês, a língua franca da ciência, a tender para língua única do discurso científico. Para além da atratividade que gera no investigador, pela possibilidade de se ser lido por uma comunidade científica mais vasta, há vários mecanismos institucionais que valorizam a publicação em inglês. Esta pesquisa foi atingida por essa atratividade. Uma parte substancial dos artigos publicados pelos investigadores selecionados estão publicados em inglês ou em revistas estrangeiras.São quatro autores, com 2 artigos cada um. Dos 8 artigos, 2 artigos são em coautoria. Tivemos em conta o facto de pelo menos um dos autores se enquadrar nos critérios estabelecidos. 
se contesta a importância, inegável, da indexação, mas assumimos com António García García (2014) que é necessário "evaluar la investigación por su mérito intrínseco y no en función de la revista en que se publica". Considero, por isso, que a avaliação por pares e a atenção à carreira de um autor "senior", aqui representada pelo estatuto de catedrático, se afiguram ser critérios mais fiáveis para a análise a desenvolver.

\section{DELIMITAÇÃO E CARACTERIZAÇÃO DO DISCURSO CIENTÍFICO}

Retomando Bakhtine (1984), os géneros de discurso têm lugar em esferas de atividade da linguagem, isto é, tipos de discurso. São lugares de discursos que "resultam do modo como uma sociedade estrutura, institucionalmente, a prática social em grandes setores de atividade" (Charaudeau 2004: $\$ 2$ ), ou seja, configuram áreas particulares de atividade social e linguística, próprias de cada sociedade. Para Maingueneau (2014: 65), um tipo de discurso define-se por uma particular rede de géneros. Em qualquer das abordagens, os tipos de discurso ${ }^{19}$ são áreas de atividade social-verbal, cujos limites são dinâmicos. São conceitos marcados pela instabilidade intrínseca das categorizações, caracterizáveis mais por "semelhanças de família" que por roturas e fronteiras estanques.

O discurso científico individualiza-se (ou dilui-se) relativamente ao discurso académico e ao discurso de divulgação científica. A primeira questão a considerar incide, pois, sobre os limites do discurso científico na relação de possível proximidade, quando não de sobreposição, relativamente a esses dois tipos de discurso. Importa sublinhar que a porosidade das fronteiras, que decorre de múltiplas inter-relações entre géneros das diferentes áreas de atividade sociodiscursiva, decorre ainda dos movimentos, alterações, derivas, que caracterizam a sociedade. ${ }^{20}$

Pese embora este continuum entre categorias, o discurso científico tem características que o distinguem do discurso académico. ${ }^{21}$ Mais ainda, a distinção entre discurso científico e discurso académico é possível e necessária. O discurso científico não pode ser sinónimo de discurso académico, pois os contextos de

19 Este é um conceito polissémico. No interacionismo sociodiscursivo, por exemplo, tipo de discurso designa um conceito diferente. O género artigo científico, é caracterizado como "discurso teórico " um dos tipos de discurso considerados (Bronckart, 1985).

20 A diversidade dos géneros dá conta da diversidade de práticas sociais no âmbito do discurso científico.

21 A discussão das fronteiras do discurso científico basear-se-á sobretudo nos chamados parâmetros externos caracterizadores dos géneros, mas que caracterizam também os tipos de discursos. 
produção são também diversos. Com efeito, quer os objetivos discursivos quer a relação entre os interlocutores são diferentes e, por isso, também os estilos são distintos (ver Marques, 2018). Há uma finalidade didática no discurso académico que está ausente do discurso científico.

São práticas sociais distintas, envolvendo interlocutores com papéis sociais e comunicativos diversos. O discurso científico é construído dentro de uma comunidade bem delimitada, a comunidade científica, constituída por pares. É enquanto cientistas que assumem um papel comunicativo, dentro de uma comunidade fechada (Charaudeau \& Maingueneau, 2002: 261).

Ainda que o espaço físico e institucional da universidade seja prototipicamente o lugar do discurso académico e do discurso científico, estes são lugares discursivos diversos. ${ }^{22}$ Como Boch $\&$ Rinck (2010), consideramos que o discurso científico é produzido no âmbito das atividades de investigação científica, como forma de construção e difusão da ciência entre pares.

Esta distinção não põe em causa que certos géneros estejam ancorados em ambos os tipos de discurso, como é o caso das teses de doutoramento ou da lição, nas provas de agregação. ${ }^{23}$

A expressão discurso académico ocorre muitas vezes como designação única e polissémica. Assim, Boch \& Rinck (2010: 8) englobam no discurso académico o discurso dos investigadores, mas também a transposição didática na universidade e, ainda, a escrita académica dos estudantes. ${ }^{24}$ Por sua vez, Hyland (2008: 2), uma referência nesta área, dá uma definição mais restritiva de discurso académico como discurso de ciência, "a guarantee of reliable knowledge" e "an objective description of what the natural and human world is actually like". Esta variabilidade na definição pode ocorrer até numa mesma publicação, como é o caso da obra editada por Salmi \& Dervin (2006). Estes identificam (p.11) o artigo

22 Na verdade, apesar da centralidade da universidade como lugar de práticas discursivas científicas, os lugares de ciência há muito deixaram de estar limitados à comunidade académica universitária. A investigação científica, e portanto, o discurso científico, estendeu-se a outros lugares, nomeadamente a laboratórios públicos e privados.

${ }^{23}$ As provas de agregação são provas públicas da carreira universitária, necessárias para aceder, em concurso posterior, à posição de catedrático em Portugal.

24 Maingueneau (2014: 155) também engloba no discurso científico "redes de géneros hierarquizados”, desde o artigo científico, como género privilegiado, aos manuais e revistas de divulgação científica, que o autor designa como "géneros considerados menos nobres". 
científico como forma canónica do discurso académico ${ }^{25}$, mas no conjunto dos autores, que participam nessa publicação, o discurso académico recebe diferentes definições. ${ }^{26}$

No discurso académico, como no discurso científico e, como veremos, no discurso de divulgação científica, também as finalidades e o estatuto sócio-comunicativo dos interlocutores constituem parâmetros de diferenciação. É uma comunidade discursiva constituída por dois grupos de interlocutores em relação interacional assimétrica, professores e estudantes, ambos empenhados num processo de ensino-aprendizagem, que impõe aos discursos uma marca forte de didatização.

Também o discurso de divulgação científica é indissociável do discurso científico. E também aqui as sobreposições ou mesmo indistinções coexistem com a diferenciação destes dois tipos de discurso. A divulgação do conhecimento ora é considerada uma das finalidades do discurso científico ora é considerada como pertencendo a outro tipo de discurso que não o científico, ainda que estreitamente ligados por um continuum de características comuns (Grossmann \& Rinck, 2004: 37).

Pese embora esta estreita relação, que se reconhece, discurso científico e discurso de divulgação científica têm prototipicamente finalidades e públicos diversos (Ramos \& Marques, 2016: 97). ${ }^{27}$ A divulgação da ciência a públicos heterogéneos cria uma comunidade, ou melhor, comunidades alargadas, diversificadas, com intervenientes que desempenham funções sociais e comunicativas diversas, especialistas, mediadores e não especialistas, numa comunidade aberta em que os

25 Segundo Boch e Rinck (2010: 8), corrente anglófona reserva o termo scientific discourse ao discurso da área das "ciências duras", usando, no caso das ciências humanas e sociais a designação de discurso académico.

26 Por exemplo, Rentel (p.59) explicitamente identifica discurso académico e discurso científico como termos sinónimos; Dervin \& Fauveau (p.105) restringem a análise a "one of the several meanings of academic discourse", no caso vertente o discurso de estudantes universitários em contexto institucional. Finalmente, Defays (p. 193) toma como objeto de investigação, também numa base de sinonímia, "o discurso académico, científico ou universitário".

27 Charaudeau (2016: 550) aponta a especificidade da finalidade primeira do discurso de divulgação: "Este ato de divulgação não se destina a tornar os indivíduos sábios ou especialistas neste ou naquele tema científico, mas a lhes permitir melhor conhecer os fenômenos do mundo". 
media sobressaem como um dos principais suportes da difusão $\mathrm{O}$ discurso de divulgação circula numa comunidade aberta. ${ }^{28}$

Não esquecendo todas as inter-relações estabelecidas entre discurso científico, discurso académico e discurso de divulgação científica, no que concerne à finalidade primeira de cada tipo de discurso a divergência pode sintetizar-se como fazer ciência, aprender ciência e divulgar ciência, respetivamente.

\section{O GÉNERO ARTIGO CIENTÍfICO}

Se, como afirma Maingueneau (2014: 63), o universo do discurso, ou o universo simplesmente, nunca se apresenta fora de uma categorização, o género de discurso é um princípio teórico fundamental, categorizador dos usos da linguagem, ou dos discursos. Falar da organização enunciativa dos discursos, dos seus modos de enunciação, é sempre colocar a questão relativamente a um género num determinado tipo discursivo. Os géneros, de acordo com a tradição de Bakhtine ${ }^{29}$, são categorias gerais de textos/discursos, são configurações de escolhas estabilizadas (temporariamente, ou "relativamente estáveis", nas palavras de Bakhtine ${ }^{30}$ ) no quadro de um grupo social-linguístico, ou área de atividade linguística. São, portanto, a memória social dos discursos produzidos numa determinada comunidade discursiva, a memória das suas regularidades, e, por isso, determinam necessariamente, ainda que de modo variável, a construção dos discursos empíri$\cos ^{31}$ Os géneros de discurso fazem parte da competência comunicativa dos falantes e têm, neste sentido, caráter normativo mais ou menos forte. ${ }^{32}$

28 «Tipicamente, o objetivo global de um texto de divulgação científica será o de tornar o alocutário mais competente, ou seja, fazer-saber e fazer-compreender. Esta precisão é importante, na medida em que permite distinguir o texto informativo (uma notícia, uma reportagem, uma breve...), que assume por objetivo ilocutório o de fazer-saber, do texto explicativo (onde se encontrarão os artigos de divulgação científica) que, ainda que incorpore igualmente o objetivo de fazer-saber, se distingue daqueles por igualmente pretender fazer-compreender...» (Ramos \& Marques, 2016: 97).

29 A referência a Bakhtine deve entender-se como equivalente a Círculo de Bakhtine. Voloshinov e Medvedev também abordaram esta questão.

30 «Tout énoncé pris isolément est bien entendu, individuel, mais chaque sphère d'utilisation de la langue élabore ses types relativement stables d'énoncés, et c'est ce que nous appelons les genres de discours. » (Bakhtine, 1984: 437)

31 Maingueneau (2014: 128) define género de discurso como um dispositivo de comunicação definido sócio-historicamente.

32 Note-se que, de acordo com Maingueneau (2000: 3), um género implica papéis e con- 
$\mathrm{O}$ artigo científico é considerado um género muito ritualizado, de caráter normativo. Ao nível da organização textual, do plano de texto mais especificamente, a estrutura $\mathrm{IMRaD}^{33}$, massivamente adotada em áreas das ciências ditas "duras", parece argumentar nesse sentido (e é apenas um exemplo, pois outros parâmetros de género, vão no mesmo sentido). Contudo há variações, e tornam-se mais notórias quando se tem como domínio de análise as ciências sociais e humanas. ${ }^{34} \mathrm{~A}$ impossível homogeneidade dos géneros realizados em textos/discursos empíricos caracteriza, de igual modo, os géneros do discurso científico, e aqui o artigo científico. ${ }^{35} \mathrm{~A}$ ritualização mais ou menos forte a que os géneros são submetidos nunca é total. ${ }^{36}$ A questão central da objetividade-subjetividade, acima considerada no âmbito do discurso científico, tem a propósito do artigo científico uma incidência ainda mais acurada.

\section{As vozes dos outros na construção da ciência}

As vozes dos outros são, paradigmaticamente, vozes de ciência, relativamente às quais o locutor se posiciona. É o caso do referenciamento aqui em análise, que abordaremos em função de cada secção do plano de texto. A variação que apontávamos neste domínio para as ciências sociais e humanas levou-nos a individualizar, independentemente das secções marcadas, três partes fundamentais no plano de organização composicional: Introdução/Enquadramento teórico-metodológico, Análise e Conclusão. ${ }^{37}$ Dada a especificidade de cada parte desta

tratos tácitos entre interlocutores, meios específicos, localizações pertinentes no tempo e no espaço, organizações textuais prototípicas, etc., isto é, um conjunto de parâmetros atualizados em cada discurso de modo variável.

33 Introdução, Metodologia, Resultados e Discussão.

${ }^{34}$ Nos artigos que selecionámos para análise esta variabilidade é notória.

35 Para efeitos de análise, considera-se texto e discurso como perspetivas diversas e indissociáveis sobre o mesmo objeto.

36 Adam (2012) propõe os termos de genericidade e efeito de genericidade para enquadrar teoricamente tal dinamismo.

37 As notas de rodapé não são aqui objeto de análise, pese embora o interesse que se lhes reconhece em termos de organização das vozes do discurso. Colocámos, no entanto como hipótese que a relegação, frequente, da citação em DD para notas de rodapé, é uma estratégia de hierarquização das vozes, vozes de autoridade colocadas na margem, não porque se conteste a autoridade mas porque são o fundo relativamente à voz do locutor que ganha autonomia discursiva e semântica. Em termos enunciativo-argumentativos, as notas de rodapé são um espaço que fortalece a imagem do locutor- 
organização textual, prevê-se que as funções das vozes e dos modos de enunciação sejam também diferentes. ${ }^{38}$

A designação adotada de referenciamento pode parecer edutora. Usamos a designação para referir formas específicas de convocação de outras vozes pelo locutor, características do artigo científico. ${ }^{39}$ Definimos aí duas categorias, a referência bibliográfica, quando há um reenvio apenas a autor e obra, subcategorizada em referência simples e referência múltipla, e a citação constituída por categorias próprias ou próximas do discurso relatado (DR), discurso direto (DD), discurso indireto (DI), discurso segundo, ilhotas textuais e discurso narrativizado. ${ }^{40} \mathrm{~A}$ perspetiva enunciativa adotada neste trabalho justifica esta escolha metodológica.

\section{Estratégias discursivas de referência bibliográfica}

Em função do número de autores referidos, classificámos as referências como simples e múltiplas, as primeiras prototipicamente constituídas por um autor, ${ }^{41}$ e eventualmente coautor(es), e uma obra, como em (2), e as segundas por vários autores e/ou várias obras (1).

(1) Partindo dos poucos elementos descritivos disponíveis (Cunha \& Cintra, 1984, Costa 2008, Raposo 2013, Vieira 2015) e convocando reflexões recentes sobre o funcionamento de itens similares noutras lín-

investigador e a orientação argumentativa do discurso.

38 Aceitar a subjetividade no artigo científico não é aceitar qualquer subjetividade, nem aceitá-la em qualquer parte da organização textual.

39 Deixamos explicitamente de lado a questão das “citações-exemplos (Rosier, 2008: 113).

40 Fløttum (2006: 30) elabora uma categorização diversa da nossa, tendo em conta uma anterior de Swales: «In our classification, somewhat different from Swales', we name our categories as follows (see Fløttum 2003e ; 2004i):

R1 - Non integral reference: The yellow sea is polluted.

R2 - Partly integral reference: The yellow sea is polluted (Clark 1999).

${ }^{\mathrm{R} 3}$ - Semi-integral reference: Clark (1999) has observed that the yellow sea is polluted.

R4 - Fully integral reference: Clark (1999) claims: "The yellow sea is polluted." / Clark (1999) claims that "the yellow sea is polluted." Veja-se ainda Rinck \& Boch (2012), entre outras tipologias propostas.

41 Esta é uma categorização que deve integrar a heterogeneidade dos casos empíricos, nem sempre facilmente integráveis numa única categoria, de que é exemplo a seguinte referência: “(na terminologia, entre outros, de Bosque, 2012) (A2). 
guas (Bosque 2012, Oxford 2010, Charnel 2010, nomeadamente), este estudo propõe-se contribuir para aprofundar... (A2).

O modo como a referência é representada graficamente produz particulares efeitos de sentido. Os parênteses, usados para delimitar autor e obra, instauram um plano desnivelado relativamente ao plano do fluxo informativo, tornam a referência supletiva, ainda que relevante em termos enunciativos:

A ausência de parênteses, por seu lado, integra o autor no fluxo informativo, como objeto de discurso mantendo, é claro, a pertinência enunciativa.

(2) ...desenvolvida no quadro da Linguística Cognitiva [...], desde o estudo seminal de Lakoff e Johnson (1980), ... (A7)

Cabe ainda referir que a integração da referência numa estrutura sintática de complementação cria um efeito de sentido de localização. Ao ser construída como lugar, permite a ocorrência de estruturas de apagamento enunciativo, como a impessoalização e a passiva. Em (3) e (4) Lobo (2003) e Lobo (2013) não são a voz, são o lugar:

(3) Em Lobo (2003), afloram-se as orações ... (A3)

(4) Em Lobo (2013), as orações introduzidas são individualizadas ... (A3)

(5) Como indicado em Matos \& Brito (2013), mesmo um verbo como dizer $[. .$.$] pode ser seguido de se + oração (A4)$

Quanto à organização composicional do discurso, as referências simples e múltiplas ocorrem, como previsível, na introdução e enquadramento teórico, quer estas secções estejam ou não graficamente individualizadas com um subtítulo. $\mathrm{Na}$ Conclusão, essa ocorrência é baixa (10 ocorrências, em 50\% dos artigos). Na Introdução/Enquadramento, a referência, simples e múltipla, cumpre o duplo objetivo de delimitar o espaço teórico-metodológico da investigação realizada e estabelecer a pertinência da investigação. Há um equilíbrio entre multirreferência e referência simples, com 20 e 22 ocorrências, respetivamente. Swales (1990: 141) refere-se a este processo de referenciamento como definição de um território, ou seja, são estratégias discursivas que visam dar conta do já dito, recortando aí o lugar teórico - espaço de investigação credibilizado - em que o locutor-investigador se coloca:

(6) Efetivamente, a Linguística Cognitiva define-se como assumindo a posição epistemológica do experiencialismo da linguagem e da cognição (Lakoff 1987, Lakoff \& Johnson 1999), como modelo centrado no significado ou conceptualização no sentido geral de qualquer ex- 
periencia mental (Langacker 1987, 1991, 1999, 2008), como modelo centrado no uso da língua (Langacker 2000) e, o que diz bem da sua natureza e do seu contributo, como modelo recontextualizador (Geeraerts 2010) (A.8)

As referências múltiplas a autores (ou a obras do mesmo autor) aduzem um efeito de credibilidade relativamente a conceitos, trabalhos ou autores que importa atualizar na superfície discursiva.$^{42}$ Não se trata de uma estratégia de exaustividade. É mais um processo de escolha que pressupõe um juízo avaliativo. Daí a possível ocorrência da multirreferência acompanhada com modalizadores:

(7) (Bosque 2012, Oxford 2010, Charnavel 2010, nomeadamente) (A2)

Ao mesmo tempo, o locutor constrói para si uma imagem de especialista. Propõe à comunidade o seu (re)conhecimento como investigador. A multirreferência tem ainda implicações na construção discursiva da imagem do outro, o alocutário, mostrado como conhecedor dos autores e obras mencionados:

(8) ...para a sua descrição, consideramos as análises realizadas na literatura linguística relevante (cf. e.o. Marques, 2004, 2013, Móia, 2015 e Peres, 2013, para o português, ou Kennedy, 1997, Schwarzchild, 2008, Sassoon, 2010 e Morzycki, 2014, para o inglês). (A2)

É na secção de Análise que se registam mais movimentos de referenciamento, quer de referências simples quer de múltiplas (considerando uma multirreferência, não os autores/obras que a constituem). Estas atingem as 41 ocorrências, enquanto as referências simples são76. ${ }^{43}$ Sobressai, nestes dados, o facto de as referências, ao serviço de um enquadramento de natureza teórica, predominarem na secção da Análise. De facto, a primeira secção, de contextualização num campo e numa questão específica, é bastante breve e a maioria dos investigadores desloca a parte substancial da ancoragem referencial para a Análise, com predomínio aí da referência simples, focando questões muito específicas. A delimitação

42 Boch, Grossmann \& Rinck (2009) ligam o processo de referência bibliográfica, especificamente, ao processo de definição de um conceito ou de um problema teórico: « Le discours scientifique veut cependant que la définition d'une notion ou d'un problème théorique, dans leur genèse ou dans les différents contours qui leur sont assignés, donne matière à référencement... ».

${ }^{43}$ Um dos artigos selecionados é a discussão de uma questão teórica. Esta característica faz aumentar o número de referências, mas não altera o quadro global. 
e a precisão da referência (mais acompanhada da explicitação das páginas que na parte da Introdução) são estratégicas para a argumentação e credibilização do trabalho apresentado.

$\mathrm{Na}$ Conclusão, as referências são residuais, apenas 10 ocorrências, das quais 6 são simples e 4 são múltiplas.

A construção da imagem credibilizada do locutor é completada pela autorreferência, em referência simples ou múltipla. O locutor mostra-se de forma explícita como membro da comunidade científica, um inter pares (em itálico, nos exemplos abaixo):

(9) No quadro da gramática generativa, vejam-se, por exemplo Brito (1991), Brito \& Duarte (2003), Móia (1996), Veloso (2013), Matos \& Brito (2013), Mioto \& Lobo (2016). (A4)

(10) utiliza o instrumentário da teoria cognitiva da metáfora e de outros programas de investigação em Semântica Cognitiva (Silva, 2006; Geeraerts \& Cuyckens, 2007). (A7)

Dados os critérios de seleção dos artigos científicos que usamos, esta forma de referência é frequente, no corpus analisado, ocorrendo como referência simples ou integrada em referência múltipla em 6 dos 8 artigos científicos, num total de 31 autorreferências. Por um lado, o locutor põe em evidência a sua experiência como investigador num determinado tópico e, por outro lado, posiciona-se com outras vozes, reconhecidas na comunidade científica como vozes de autoridade. É ainda de salientar que 23 dos casos de autorreferência ocorrem na secção de Análise, contra 8 na Introdução/Enquadramento teórico-metodológico. O locutor constrói um ethos de experiência, de especialista da área. Mas cria também expectativas relativamente ao trabalho realizado, quer seja numa perspetiva de continuidade e aprofundamento quer de possíveis divergências face a trabalhos e quadros teóricos diversos.

Considerando o quadro global que o referenciamento simples e múltiplo e autorreferência permitem traçar, os investigadores privilegiam trabalhos singulares em $51,5 \%$ dos casos contra $33,1 \%$ de multirreferência e $15,3 \%$ de autorreferência. ${ }^{44}$ Há uma imagem global, muito sistemática, de conhecimento alargado,

44 Há ainda uma outra informação quantitativa interessante, dada pela secção de referências de cada artigo. Exceto um caso singular, de um artigo de discussão teórica, unicamente, são citados, por artigo, entre 11 e 28 autores, para um conjunto de obras entre 16 e 35. Este é um dado interessante para um estudo comparativo entre tradições científicas e entre comunidades diversas. 
mas sobretudo de acuidade teórica que se impõe à primeira, na construção do conhecimento científico, associada à credibilidade do próprio locutor, apresenta$\mathrm{da}$, em valores quantitativos, com alguma parcimónia, o que protege a sua face. Valorizando o próprio trabalho, em autodialogismo, o locutor dá destaque à voz dos outros, seus pares, e o heterodialogismo impõe-se.

\section{Estratégias discursivas de citação}

A citação é uma categoria que engloba os modos de representação do discurso relatado (formalmente, é acompanhada de referência simples). Tais modos de representação são estratégicos, participam da orientação argumentativa do discurso (Amossy, 2000), porque convocam necessariamente o posicionamento do locutor relativamente ao discurso relatado e, especificamente, ao seu locutor. Brès \& Nowakowska (2004: 75), entre outros, lembram que o discurso relatado é um fenómeno de desdobramento enunciativo, constituído por dois enunciados hierarquizados. Sendo uma mediação de um discurso outro, uma enunciação numa enunciação, o DR é feito a partir do olhar do locutor. No excerto abaixo, a integração de discurso relatado no discurso é acompanhada de um juízo avaliativo, através de mecanismos linguístico-discursivos diversos, desde as escolhas lexicais ao discurso indireto e ao discurso segundo agregado a estruturas de impessoalização. O juízo avaliativo desencadeado pela escolha lexical de "escassas referências" orienta o discurso para a manifestação de uma necessidade, reforçada nas expressões que enquadram os discursos a relatar "aborda brevemente" e "afloram-se”. São juízos avaliativos com valor argumentativo, justificam a criação de um nicho (Swales, 1990: 141) ${ }^{45}$ e asseguram em simultâneo a pertinência do trabalho realizado, por insuficiência de exploração do tema em trabalhos anteriores:

(11) São escassas as referências às orações introduzidas por 'sem' (ou expressão equivalente noutras línguas) na literatura sobre subordinadas adverbiais. Kortmann (1996) considera que as subordinadas adverbiais introduzidas por 'without' expressam concomitância negativa, e Hengeveld (1998) aborda brevemente as mesmas construções, rotulando-as de adverbiais de circunstância negativa. Em Lobo (2003), afloram-se as orações adverbiais de modo, instrumento ou meio, que a autora reconhece constituírem uma classe heterogénea, raramente referida nas gramáticas tradicionais portuguesas. (A3)

Importa, pois, analisar a variabilidade dessa presença.

45 A par de estratégias discursivas de presença ou apagamento do locutor. 
Como referido acima, não há uma distinção clara entre as duas categorias assinaladas, referenciação e citação, uma questão que não é sequer privativa desta temática, antes decorre da assunção da heterogeneidade como constitutiva do processo de categorização. O discurso narrativizado ${ }^{46}$ dá efetivamente conta de um continuum de procedimentos discursivos entre a referência simples, como evocação de um autor/obra e a citação ainda que condensada:

(12) O PPC corresponde a uma estrutura de iteração com um alcance mais vasto que o que é proposto em Cunha (2006) e que a definição dada por este autor requererá provavelmente alguma reformulação. (A1)

Por sua vez, o Discurso Direto é residual, nos artigos analisados. Surge tipograficamente delimitado, ainda que segundo normas diversas das tradicionalmente apontadas, como em (13), em que a transição marcada por dois pontos é ambígua, só se recuperando o caráter de citação na referência simples posposta.

(13) Ou, numa formulação eventualmente mais transparente: as construções condicionais-concessivas têm em comum as seguintes propriedades [...] (Lobo, 2013, p.20) (A)

(14) E nas palavras de Lopes (2005: 149), “ a significação é o ponto de partida e o ponto de chegada de toda a atividade linguística” (A5)

Em termos quantitativos, a "literalidade"47 da citação, através do relato em Discurso Direto, não é preferencial, num discurso que valoriza o conhecimento partilhado entre especialistas numa interação. Por outro lado, e ainda que não podendo ser causa decisiva, não é de desvalorizar uma necessidade de economia do espaço, dado ser cada vez mais usual as revistas científicas imporem um limite

${ }^{46}$ Rosier (2008: 105-107): "C'est un discours citant sans discours cité, c'est un discours qui est traité comme un événement [...] le DN permet de mentionner qu’un discours a eu lieu, sans donner d'existence effective au discours cité. [...]. Avec le DN, on est renseigné sur la thématique du discours, sur l'acte de parole, sur les conditions de production de l'acte de parole." E um discurso de condensação de uma enunciação.

47 Só de forma aproximada se pode usar o termo literalidade, dada a contextualidade do sentido. Mantemos o termo para referir o que outros autores, de modo também redutor, chamam de citação integral. O DR é uma manipulação do discurso alheio, porque o locutor cede o lugar ao locutor citado (de modos diferentes, se é DD, DI ou outros), mas é uma cedência argumentativamente orientada, o locutor cede a palavra nos termos que previamente determinou. 
de páginas, palavras ou mesmo espaços. Ora, a citação direta é o mecanismo mais extenso à disposição do locutor para o relato de discurso e o referenciamento em geral.

Os verbos introdutores do DI são verbos de opinião, modalizados. Nos artigos analisados, são verbos como argumentar, considerar, sugerir, notar. Mostram o processo de interpretação do locutor, agregando nomeadamente o discurso relatado ao seu desenvolvimento enunciativo-discursivo ou à responsabilização pelo PDV expresso:

(15) Lecarme (2008: 210) considera que em Somali as orações condicionais são relativas livres modalizadas (A6) e Haegeman (2010: 220221) faz notar que mesmo línguas como o inglês ou o francês apresentam estratégias de relativização para expressar condicionais..." (A6)

(16) Constatações deste tipo levaram Bosque (2012) a argumentar que, no uso de dependência interna (A2)

(17) Wilson (2005) fala de mente coletiva, sugerindo que o nosso cérebro está especialmente preparado... (A8)

Finalmente, as ilhotas textuais integram um fragmento das palavras do locutor citado no discurso do locutor citante, permitindo um afastamento por desresponsabilização enunciativa. São sempre assinaladas graficamente. Nos exemplos abaixo, o itálico e as aspas marcam este estatuto:

(18) Wilson (2005) fala de mente coletiva, sugerindo que o nosso cérebro está especialmente preparado para ... (A8)

(19) Riemsdijk (2007) designa este tipo de relativas livres como "transparentes", e apresenta os seus contextos de ocorrência característicos... (A6)

Das formas de citação em discurso relatado, as mais frequentes são o discurso narrativizado e o discurso segundo ou modalizado, formas não canónicas, nos confins do discurso relatado. ${ }^{48}$ De facto, a citação é, em termos das estruturas sintáticas que caracterizam os modos de DD e DI, muito pouco canónica e caracteriza-se por uma variedade de estruturas.

Trata-se de uma forma de relato do discurso, próxima do discurso indireto, mas introduzida por um complemento com função de modalizador:

(20) Note-se que, de acordo com Landman \& Rothstein (2012b), a decisão de gerar mais fases transtemporalmente idênticas em processos iterativos é uma decisão contextual. (A1)

48 Rosier (2008: 99) intitula assim o capítulo que trata de formas não canónicas de DR. 
Este marcador de modalização, "de acordo com", não condiciona o locutor a um posicionamento de convergência. É similar a "segundo X”. Assim, trata-se de atribuir a responsabilidade do PDV a um outro locutor, para sobre ele encadear o discurso,

Para além da argumentação no discurso, em que o processo de referenciamento é uma estratégia fundamental, o discurso relatado permite ao locutor argumentar a favor de uma determinada conclusão, tomando o discurso do outro como argumento ou contra-argumento, atenuando ou matizando, neste caso, a relação com o outro:

(21) Para além disso, de acordo com Cunha (2006), a iteração requer um intervalo [...]; pelo contrário, o intervalo a que corresponde o PPC pode ter uma extensão variável. (A1)

(22) Segundo Ambar, esse núcleo vazio teria de ser adequadamente regido na posição inicial da frase [...] o que motivaria [...]. Porém, o movimento V não é necessário. (A4)

Mais frequente com o discurso indireto, não é incompatível com o DD:

(23) De acordo com Landman e Rothstein (2012b), "um estado s é homogéneo sse, para cada ...” (A1)

Por fim, o discurso narrativizado dá conta da frequência da condensação dos discursos dos outros, e próprios também, representados frequentemente no discurso como propostas para o conhecimento científico. A escolha destes itens lexicais ("proposto", "posição", nos exemplos abaixo) cria um efeito de sentido que valoriza a argumentação e a discussão (com vista à legitimação) dos resultados obtidos:

(24) Contrariamente ao que é proposto em Cunha (2006) (A1)

(25) Idêntica posição é defendida em Silva (2007) (A)

\section{CONCLUSÕES}

Seguindo a proposta de Maingueneau (2000:11) sobre «... quem está autorizado a falar ou a ser destinatário...» no discurso científico, demos espaço à análise da construção da voz autorizada do locutor na relação com as vozes que traz para o discurso e que designamos como referenciamento, em artigos científicos da área das Ciências da Linguagem, da autoria de investigadores seniores, em revistas científicas portuguesas.

Retomar, reorientar, contestar os pares. Todos os locutores recorrem às mesmas estratégias. Sob a responsabilidade do locutor, ainda que este não se respon- 
sabilize por todos os PDV de igual modo, há uma conjunção de vozes que funciona em rede, geradora de uma coerência dialógica global, a fim de construir uma voz única, uma abstração, que se pode designar como a voz da ciência. Neste processo a credibilidade do locutor é assegurada. O artigo científico é, assim, construído em função de uma intersubjetividade compartilhada, que não põe em causa o rigor do conhecimento, mas o enforma.

Ao considerar o discurso e não o enunciado, passamos da constatação da proliferação de vozes para a análise das relações que o locutor com elas estabelece a nível local e global. Gerir o dialogismo, em negociação com o alocutário, é uma das tarefas do locutor na construção da textura enunciativa coesa e coerente. O referenciamento, nas duas categorias identificadas, mobiliza mecanismos linguísticos e discursivos diversos, mas a escolha operada pelo locutor materializa uma estratégia de argumentação discursiva e de legitimação de si próprio, por um lado, e participa, em particular nos casos de citação, na construção de um movimento argumentativo importante, quer como argumento mais forte que legitima a proposta do locutor quer como contra-argumento, relativamente ao qual a adequação do raciocínio desenvolvido se acentua, com vista à construção do conhecimento científico num domínio específico.

Dos mecanismos linguístico-discursivos selecionados - referência simples, multirreferência, autorreferência e citação - a condensação dos conteúdos relatados prevalece, ativando, quer pela simples remissão ao autor e obra quer por meios diversos de citação, os conteúdos compartilhados pela comunidade científica.

$\mathrm{Na}$ análise realizada, sobressai ainda o modo como os locutores dos diferentes artigos se posicionam relativamente ao conhecimento científico em construção, sistematicamente designado como "proposta" ou itens semanticamente similares.

Apesar das estratégias discursivas analisadas, ficaram por referir outras estratégias e mecanismos de construção da voz do locutor e de outras vozes mais ou menos identificadas, e suas funções no discurso científico, já estudadas, no entanto, noutros trabalhos.

Acentuámos a dimensão social da construção dos discursos científicos, o que implica a necessidade de analisar o mesmo género noutras disciplinas e noutras comunidades científicas nacionais e internacionais para obter uma análise mais completa. Descrever e explicar as características do discurso científico passa ainda pela análise de outros géneros. Daí a necessidade de continuar numa perspetiva contrastiva, com outras áreas da ciência, com outras tradições de investigação, em português e noutras línguas, e noutras variedades da mesma língua. 


\section{REFERÊNCIAS}

Adam, J.-M. (2015). Le problème du texte dans l'analyse du discours développée par Dominique Maingueneau (1976-2014). In Angermuller, J. \& Philippe, G. (orgs). Analyse du discours et dispositifs d'énonciation. Autour des travaux de Dominique Maingueneau (pp.41-50). Limoges: Lambert Lucas.

Adam, J.-M. (2012). Analyse textuelle des discours: niveaux ou plans d'analyse. Filol. linguist. port., n. 14(2), 191-202.

Adam, J.-M. (2010). A análise textual dos discursos: entre Gramáticas do Texto e Análise do Discurso. Eutomia. Revista de Literatura e Linguística, v.1, nº 06, 1-14.http:// dx.doi.org/10.19134/eutomia-v1i06.

Amossy, R. (2000). L'argumentation dans le discours, Paris, Nathan.

Authier-Revuz, J. (1984). Hétérogénéité(s) énonciative(s). Langages $n^{\circ}$ 73, 98-111.

Authier-Revuz, J. (1982). Hétérogénéité montrée et hétérogénéité constitutive: éléments pour une approche de l'autre dans le discours. DRLAV 26, 91-151.

Bakhtine, M. (1984). Esthétique de la Création Verbale. Paris: Gallimard

Benveniste, E. (1970). L'appareil formel de l'énonciation. Langages 17, 12-18.

Boch F. \& Rinck, F. (2010). Pour une approche énonciative de l'écrit scientifique. Lidil [En ligne], 41, 5-14 (acesso: 31 ago. 2013). http://lidil.revues.org/3004

Boch, F., Grossmann, F. \& Rinck, F. (2009). Le cadrage théorique dans l'article scientifique: un lieu propice à la circulation des discours. In Lopez Munoz J.M., Marnette, S. \& Rosier, L. (eds), Actes du Colloque International Ci-dit (pp. 23-42) Québec : Nota Bene.

Brès, J. \& Nowakovska, A. (2005). Dis-moi avec qui tu dialogues, je te dirai qui tu es... De la pertinence de la notion de dialogisme pour l'analyse du discours. Marges Linguistiques, 137-153. http://www.marges-linguistiques.com. (acesso: 22 de novembro de 2016).Bronckart, J.-P. (org.) (1985). Le Fonctionnement des discours : un modèle psychologique et une méthode d'analyse. Neuchâtel : Delachaux et Niestlé.

Charaudeau, P. (2016). Sobre o discurso científico e a sua midiatização. Calidoscópio Vol. 14, n. 3, 550-556.

Charaudeau, P. (2012). Pour une interdisciplinarité focalisée. Réponses aux réactions. Revue Questions de communication, $\mathrm{n}^{\circ} 21$. (acesso: 8 de setembro de 2015)

http://www.patrick-charaudeau.com/Pour-une-interdisciplinarite, 283.html

Charaudeau, P. (2004). Visadas discursivas, gêneros situacionais e construção textual In Machado, I. L. \& Mello R. (ed), Gêneros - reflexões em análise do discurso (pp.1341). Belo Horizonte, Nad/Fale-UFMG.

Charaudeau, P. (2002). À quoi sert d'analyser le discours politique ? Análisi del discurs politic, IULA-UPF, Barcelone.

Charaudeau, P. \& Maingueneau, D. (ed). 2002. Dictionnaire d'analyse du discours. Paris : Seuil Ducrot, O. (1984). Esquisse d'une théorie polyphonique de l'énonciation. Le dire et le dit (pp. 171-233). Paris: Minuit. 
Defays, J.-M. (2006). Prolégomènes `aune analyse critique des discours universitaires. In Suomela-Salmi, E. \& Dervin, F. (eds.), Perspectives interculturelles et interlinguistiques sur le discours académique. Crosscultural and crosslinguistic perspectives on academic discourse (ebook) (pp.193-219). Department of French Studies: The University of Turku, Finland.

Dervin, F. \& Fauveau, S. (2006). Problems in the construction of argumentative speech in a foreign language : the instability of discourse objects. In Suomela-Salmi, E. \& Dervin, F. (eds.), Perspectives interculturelles et interlinguistiques sur le discours académique. Crosscultural and crosslinguistic perspectives on academic discourse (ebook) (pp.16-44). Department of French Studies: The University of Turku, Finland.

Fløttum, K. (2006). The typical research article does it exist?. In Salmi, E. \& Dervin, F. (eds.), Perspectives interculturelles et interlinguistiques sur le discours académique. Crosscultural and crosslinguistic perspectives on academic discourse (ebook) (pp.1644). Department of French Studies: The University of Turku, Finland. http://www. hum.utu.fi/ranskakk/fran.htm

Fløttum, K. (2002). Polyphonie et typologie revisitées. In Olsen, M. (éd). Polyphonie linguistique et littéraire, V. Roskilde: Samfundslitteratur Roskilde.

Fonseca, J. (1994). Pragmática Linguística - Introdução, Teoria e Descrição do Português. Porto: Porto Editora.

García, García, A. (2014). La tiranía del factor de impacto. Actualidad en farmacología y terapéutica, Vol. 12, No. 1, 2014, 8-13.

Grossmann, F. (2010). The scientific author. Revue d'anthropologie des connaissances, vol4, n'3.

Grossmann, F. \& Rinck, F. (2004). La surénonciation comme norme du genre. L'exemple de l'article de recherche et du dictionnaire de linguistique. Langages 156, 34-50.

Gustfield, J. (1976). The literary rhetoric of science: comedy and pathos in drinking driver research. American sociological review vol.41 nº 1, 16-34.

Hailon, F. (2012). L'énonciation dans les pratiques de l'hétérogène. Revue TR ANEL 56. Travaux Neuchâtelois de Linguistique, 119-134.

Hyland, K. (2008). Persuasion, interaction and the construction of knowledge. IJES, vol. $8(2), 1-23$.

Hyland, K. (2002). Authority and invisibility: Authorial identity in academic writing. Journal of Pragmatics, 34, 1091-1112.

Hyland, K. 2001. Humble servants of the discipline? Self-mention in research articles. English for specific purposes 20 (3), 207-226.

Hyland K. (1996a). Talking to the academy: forms of hedging in science research articles. Written Communication, vol. 13, 251-281.

Hyland, K. (1996b). Writing without conviction? Hedging in scientific research articles. Applied linguistics 17 (4), 433-454.

Maingueneau, D. (2014). Discours et analyse du discours. Paris: A. Colin. 
Maingueneau, D. (2010). Manuel de linguistique pour les textes littéraires. Paris : Armand Colin.

Maingueneau, D. (2006). Análise do Discurso: uma entrevista com Dominique Maingueneau. Revista Virtual de Estudos da Linguagem - ReVel, vol.4, n. ${ }^{\circ} 6$ (Trad. G. Á. Othero). www.revel.inf.br

Maingueneau, D. (2000). Analisando discursos constituintes. Revista GELNE, vol2, $\mathrm{n}^{\circ} 2,1-12$.

Maingueneau, D. \& Cossutta, F. (1995). Les discours constituants. Langages 117, 112125.

Marques, M. A. (2018). Práticas discursivas em contexto universitário: da leitura a escrita. In Momesso, M. R., Campato Jr, J., Marques, M. A. \& Corsi, F. (Orgs). Leitura e Escrita. Experiencias e perspectivas a luz de uma abordagem discursiva (pp.103122). Porto Alegre: CirKula.

Marques, M. A. (2015). Para uma análise linguística dos discursos. A heterogeneidade enunciativa como princípio ordenador da investigação. Revista de Filoloxía Galega $16,107-121$.

Prestigiacomo, C. (2016). Ciencia y manipulation discursiva en Legiones y Falanges : «Características raciales del comunismo». In Prestigiaciomo, C. (org.), Identità, totalitarismi e stampa. Ricodifica linguistico-culturale dei media di regime (pp.257-276). Palermo: New Digital Frontiers srl.

Rabatel, A, (2018). Pour une reconception de l'argumentation à la lumière de la dimension argumentative des discours. Argumentation et analyse du discours, 20, 1-19. DOI : $10.4000 /$ aad.2493

Rabatel, A. (2015). Points de vue en confrontation substitutifs ou cumulatifs dans les contrepèteries (in absentia). In Winter-Froemel, E. \& Zirker, A. (eds), Enjeux du jeu de mots. Perspectives linguistiques et littéraires (pp.31-64) De Gruyter

Rabatel, A. (2012). Positions, positionnements et postures de l'énonciateur. - TRANEL 56. Travaux Neuchatelois de Linguistique, 23-42.

Rabatel, A. (2005). La part de l'énonciateur dans la construction interactionnelle des points de vue. Marges Linguistiques 9. M.L.M.S. Publisher, http://www.marges-linguistiques.com (acesso : 12 de outubro de 2012).

Rabatel, A. (2004b). La déliaison des énonciateurs et des locuteurs dans la presse satirique. Langage et société 110, 7-23

Ramos, R. \& Marques, M. A. (2016). Traços de didaticidade em discursos de divulgação científica mediática. O caso de uma edição especial “verde” da revista Visão. Revista de Estudos do Discurso - REDIS 5, 93-118.

Rentel, N. (2006) Evaluation in Italian and French research Articles in Linguistics. In Suomela-Salmi, E. \& Dervin, F. (eds.), Perspectives interculturelles et interlinguistiques sur le discours académique. Crosscultural and crosslinguistic perspectives on academic discourse (ebook) (pp.59-71). Department of French Studies: The University of Turku, Finland. 
Reutner, U. (2010). De nobis ipsis silemus? Les marques de personne dans l'article scientifique. Lidil 41: 79-102. http://lidil.revues.org/3013.

Rinck, F. (2010). L'analyse linguistique des enjeux de connaissance dans le discours scientifique. Un état des lieux. Revue d'Anthropologie des connaissances vol.4, n³, 427-450.

Rosier, L. (2008). Le Discours rapporté en français. Paris: Ed. Ophrys

Suomela-Salmi, E. \& Dervin, F. (eds.)(2006). Perspectives interculturelles et interlinguistiques sur le discours académique. Crosscultural and crosslinguistic perspectives on academic discourse (ebook) Department of French Studies: The University of Turku, Finland,

Swales, J. (2004). Research Genres. Exploration and Applications. Cambridge: Cambridge University Press.

Swales J. (1990). Genre analysis: English in academic and research settings, Cambridge: Cambridge University Press.

\section{ANEXO: ARTIGOS CIENTÍFICOS ANALISADOS}

A1: Oliveira, F. et al. (2018). Sobre a natureza homogénea do Pretérito Perfeito Composto em Português Europeu. Revista de Estudos Linguísticos da Universidade do Porto Vol. 13, 57-78.

A2: Lopes, A. C. (2015). A polifuncionalidade de mesmo no português europeu contemporâneo. Diacrítica 32(1), 43-67

https://doi.org/10.21814/diacritica.93

A3: Lopes, A. C. (2015). Contributos para a caracterização das orações adverbiais introduzidas por sem em português europeu contemporâneo. Estudos Linguísticos/ Linguistic Studies, 10,185-196.

A4: Matos, G. \& Brito, A. (2018). Relativas livres e interrogativas parciais: paralelos e diferenças. Revista da Associação Portuguesa de Linguística n4, 152-167.

A5: Oliveira, F. et al. (2019). Revista da Associação Portuguesa de Linguística nº5, 94107.

A6: Brito, A. \& Matos. G. (2018). Relativas livres e interrogativas parciais: como Óscar Lopes viu algumas destas construções. Revista de Estudos Linguísticos da Universidade do Porto Vol. 13, 29-56.

A7: Silva, A. (2015). O que sabemos sobre a crise económica pela metáfora. Conceptualizações metafóricas da crise na imprensa portuguesa. Media \& jornalismo

A8: Silva, A. (2015). Discurso na mente e na comunidade. Para a sinergia entre Linguística Cognitiva e Análise (Crítica) do Discurso. Revista portuguesa de Humanidades. Estudos Linguísticos, 